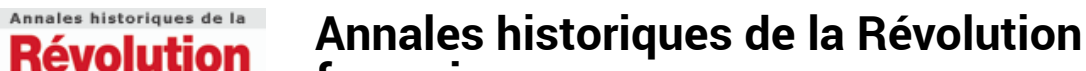

française française

367 | janvier-mars 2012

Théâtre et révolutions

\section{Wilfried UITTERHOEVE, Koning, keizer, admiraal. 1810. De ondergang van het Koningkrijk Holland}

\section{François Antoine}

\section{OpenEdition}

Journals

Édition électronique

URL : https://journals.openedition.org/ahrf/12396

DOI : 10.4000/ahrf.12396

ISSN : $1952-403 X$

Éditeur :

Armand Colin, Société des études robespierristes

Édition imprimée

Date de publication : 1 mars 2012

Pagination : 238-239

ISSN : 0003-4436

Référence électronique

François Antoine, «Wilfried uitTerhoeve, Koning, keizer, admiraal. 1810. De ondergang van het Koningkrijk Holland ", Annales historiques de la Révolution française [En ligne], 367 | janvier-mars 2012, mis en ligne le 12 septembre 2012, consulté le 01 juillet 2021. URL : http://journals.openedition.org/ahrf/12396 ; DOI : https://doi.org/10.4000/ahrf.12396

Ce document a été généré automatiquement le 1 juillet 2021.

Tous droits réservés 


\title{
Wilfried UITTERHOEVE, Koning, keizer, admiraal. 1810. De ondergang van het Koningkrijk Holland
}

\author{
François Antoine
}

\section{RÉFÉRENCE}

Wilfried UITTERHOEVE, Koning, keizer, admiraal. 1810. De ondergang van het Koningkrijk Holland, Nijmegen, Vantilt, 2010, 230 p., ISBN 9061683106, $15 €$.

1 En 2013, les Pays-Bas connaîtront une vaste marée orange marquant le bicentenaire du retour d'exil du prince Guillaume d'Orange. Ce dernier prit dans un premier temps le titre de «Prince souverain des Pays-Bas » pour se transformer le 16 mars 1815 en celui de roi des Pays-Bas afin d'anticiper le retour de Napoléon débarqué le $1^{\mathrm{er}}$ mars à GolfeJuan. Depuis l'orange se confond avec les couleurs nationales néerlandaises et bon nombre de Néerlandais méconnaissent l'existence de Louis-Napoléon qui durant un règne éphémère de quatre années fut leur premier roi. Dans cette optique, l'ouvrage de Wilfried Uitterhoeve se rattache au courant historique néerlandais qui depuis quelque temps vise à mettre en perspective la geste fondatrice orangiste.

2 Pour le grand public néerlandais, «Koning, keizer, admiraal» constitue un titre accrocheur en faisant référence à une publicité largement diffusée dans les années soixante-dix. Dans un style direct et agrémenté d'expressions imagées et de citations tirées de la correspondance de l'époque, Wilfried Uitterhoeve nous relate une véritable tragédie dont les principaux protagonistes sont, entre autres, le «koning» LouisNapoléon, le « keizer » Napoléon et l' "admiraal » Carel Hendrik Verhuel. Cet épisode pénible de l'histoire contemporaine néerlandaise aboutit le 10 juillet 1810 à la perte de souveraineté des Pays-Bas et leur annexion pure et simple à l'Empire français.

3 En dix chapitres et dix points de conclusion, l'auteur réussit la gageure de le décrire sous la forme d'un véritable roman dramatique qui se joua en trois actes. Le premier 
tableau décrit les tensions entre Napoléon et Louis-Napoléon qui atteignirent leur paroxysme au cours de l'année 1809. Placé en 1806 à la tête des Pays-Bas, le jeune frère de l'empereur devait, en principe, répondre aux priorités commerciales et militaires de la France. Mais Louis-Napoléon ne fut pas d'humeur à jouer les souverains de pacotille d'un État satellite et privilégia les intérêts de ses sujets, le menant inévitablement au conflit avec Napoléon. L'application du blocus continental constitua l'une des principales pierres d'achoppement entre les deux frères Bonaparte.

4 L'expédition anglaise de Walcheren au cours de l'été 1809 décida l'empereur que la France devait disposer au Nord de frontières naturelles en amputant le royaume de Hollande des provinces de Brabant et de Zélande. Maintenu en résidence surveillée à Paris, le roi Louis-Napoléon manœuvra dans le faible espace qui lui restait et ne put assurer un bref sursis à son royaume qu'à la faveur du mariage de Napoléon avec Marie-Louise, plaçant les Bonaparte au même rang que les Habsbourg, les Romanov et les Hohenzollern. L'empereur préféra à ce moment éviter tout affrontement au sein de sa famille, comme le risque d'une opération militaire contre le réduit hollandais qui avait déjà par le passé mis en échec les troupes de Louis XIV.

Enfin, le coup de grâce fut porté au printemps 1810 lorsque Napoléon annexa le restant du royaume de Hollande afin d'étendre les côtes de l'Empire jusqu'au Danemark. Pour compléter le tableau, le roi Louis-Napoléon qui avait définitivement opté pour la Hollande, fut abandonné par une bonne partie de l'élite néerlandaise gagnée progressivement par le défaitisme.

6 L'ouvrage de Wilfried Uitterhoeve ne se base pas sur des trouvailles archivistiques, ni sur une bibliographie exhaustive sur le sujet, mais sur une bonne part des documents publiés au XIX ${ }^{\mathrm{e}}$ siècle dans la Correspondance de Napoléon $I^{e r}$, le rapport du ministre des Affaires étrangères Willem Frederik Roëll ou la correspondance entre les deux frères Bonaparte publiée par Félix Rocquain. En agençant les passages de lettres échangées entre le mois de novembre 1809 et le mois juillet 1810 (pour l'essentiel traduits du français vers le néerlandais), l'auteur met en relief le roi Louis-Napoléon qui apparaît comme un personnage mélancolique et hésitant, mais également comme un gestionnaire hors pair qui réussit à faire aboutir dans plus d'un domaine la dynamique de modernisation de l'État néerlandais mis en œuvre durant la période de la République batave. Au travers de ses tiraillements entre une loyauté à son frère, empereur des Français, et à sa nouvelle patrie, la Hollande, le lecteur peut appréhender la perte progressive de souveraineté des anciennes Provinces-Unies et l'annonce d'un renouveau national néerlandais. 